American Journal of Agricultural and Biological Sciences 5 (1): 37-42, 2010

ISSN 1557-4989

(C) 2010 Science Publications

\title{
Viability of Lactobacillus delbrueckii Under Human Gastrointestinal Conditions Simulated In Vitro
}

\author{
Karina Cruz Pacheco, Gustavo Valencia del Toro, \\ Fabián Robles Martínez and Enrique Durán-Páramo \\ Department of Bioprocess, Unit of Biotechnology (UPIBI), \\ National Polytechnic Institute (IPN), Ave. Acueducto s/n, Col. Barrio La Laguna Ticomán, \\ México, 07340, Distrito Federal
}

\begin{abstract}
Problem statement: Lactobacillus delbrueckii subsp. bulgaricus is a lactic bacteria mostly used in the production of yoghurt and it has an important probiotic activity that brings benefits to the human body. However, the gastrointestinal tract has aggressive conditions, such as the acid $\mathrm{pH}$ in the stomach and the bile in the duodenum, that reduce the viability of this bacteria. Approach: In order to evaluate the effect of the human gastrointestinal conditions on Lactobacillus delbrueckii's viability, a simulated in vitro gastrointestinal system was designed, which consisted of two reactors where stomach and human small intestine conditions were simulated. Results: Lactobacillus delbrueckii cells were treated in human gastric conditions simulated in vitro (gastric juice adjusted to $\mathrm{pH} 2,37^{\circ} \mathrm{C}, 90$ min and $50 \mathrm{rpm}$ ) and in intestinal conditions simulated in vitro (pancreatic juice adjusted to $\mathrm{pH} 6.8$, $37^{\circ} \mathrm{C}, 150 \mathrm{~min}$ and $50 \mathrm{rpm}$ ) and in presence of a sample of food or beverages. A sample of typical Mexican food was added and at the end of the treatment $73 \%$ of the cells remained viable. This means 36.5 times more viability with respect to the cells treated under the same conditions in presence of a sample of milk with $8 \%$ starch. At the end of the treatment, the viability of cells treated in simulated in vitro gastrointestinal juices without sample of food or beverage (blank) was $1 \%$. Conclusion: The results indicated that the in vitro simulated human gastrointestinal conditions were aggressive to the Lactobacillus delbrueckii's viability. To minimize this negative effect it is suggested that probiotics be consumed with some food because this could increase the probability that the bacteria reach the human colon in a large number and carry out their probiotic effect.
\end{abstract}

Key words: Probiotics, functional food, viability

\section{INTRODUCTION}

The interest to know the role of probiotic lactic bacteria in human's health has (Chandramouli et al., 2004) been increasing for the last 20 years (Marteau et al., 1997). Nowadays, the dairy industry has incorporated lactic bacteria not just as fundamental part in the production of lactic fermented food, but as an active ingredient of the well known "functional foods" like yoghurt and fermented milks, that have probiotics effects in the human organism and are intended to solve gastrointestinal problems as lactose intolerance and constipation (Sanders and Klaenhammer, 2001; Walker and Duffy, 1998). In recent years it has been proved that probiotic lactic bacteria brings some protection against pathogen microorganisms (Casas and Dobrogosz, 2000; Hamilton-Miller et al., 1999), stimulates the immune system (Aattouri et al., 2002) and it even contributes to the lessening of colon cancer. Probiotic lactic bacteria belong principally to the genus Lactobacillus and Bifidobacterium and yield their benefits in the human large intestine. To accomplish the probiotic effect, lactic bacteria must survive viable and at a large number to the colon.

Some authors mention that lactic bacteria in yoghurt must be active and not below $10^{7}$ Colony Forming Units (CFU) per gram of product concentration (Ouwehand and Salminen, 1998). However, there are several studies that show that lactic bacteria contained in the yoghurt might lose their viability during the stage of storage in refrigeration and during the path along the upper gastrointestinal tract of the consumer (Ouwehand and Salminen, 1998; Kailasapathy and Rybka, 1997; Dave and Shah, 1998).

Corresponding Author: Enrique Durán-Páramo, Department of Bioprocess, Unit of Biotechnology (UPIBI),

National Polytechnic Institute (IPN), Ave. Acueducto s/n, Col. Barrio La Laguna Ticomán, México, 07340, Distrito Federal Tel: 5557296000/ext. 56347 Fax: 5557296000 ext. 56305 
The main factors in the gastrointestinal human tract that can affect the bacterial viability before the lactic bacteria reach to the human colon are the acid $\mathrm{pH}$ in the stomach and the bile in the duodenum.

Several systems have been developed to simulate the physicochemical conditions in vitro present in the gastrointestinal human tract and to allow the study of lactic bacteria viability. The simulation systems range from simple ones where the lactic bacteria is treated in solutions of acid medium and solutions of hepatic bile (Fávaro-Trindade and Grosso, 2002; Huang and Adams, 2004), to more complex systems that simulate the human gastrointestinal tract to study the probiotic lactic bacteria interactions within the intestinal microbial environment or determine the effect of probiotic lactic bacteria and symbiotic products in the human intestinal microbiota (De Boever et al., 2000; Mainville et al., 2005). Minekus et al. (1995) proposed an intestinal human tract model that contained four chambers to simulate the stomach, duodenum, jejunum and ileum. Other viability studies of lactic bacteria have been performed in vivo in pig intestine (Iyer et al., 2005).

In this research, we studied the viability of Lactobacillus delbrueckii subsp. bulgaricus. First it was treated in acid medium with addition of enzymes such as pepsin and mucin to simulate in vitro the human stomach conditions and after that, in pancreatic juice that contained pancreatin, bile and mucin, thus simulating the human small intestine conditions in vitro. Also, the effect of samples of meal and beverages (stimulant and alcoholic) on bacterial viability was evaluated.

\section{MATERIALS AND METHODS}

Microorganism: The Lactobacillus delbrueckii subsp. bulgaricus NRRL-734 strain was obtained from the United States Department of Agriculture and it was preserved in MRS agar contained in Petri plates (Man and Rogosa, 1960).

Design of a in vitro simulation system of the human gastrointestinal conditions: The gastrointestinal simulation system in vitro consisted of 2 jacketed bioreactors with removable lids and a capacity of $500 \mathrm{~mL}$, made of borosilicate glass. The bioreactors lids had 5 entries to supply $\mathrm{HCl}, \mathrm{NaOH}$ solutions, to take the samples and to place the $\mathrm{pH}$ electrode and the thermometer.

The bioreactors were connected in sequence to a bath with controlled temperature, which maintained them to $37^{\circ} \mathrm{C}$ to the physiological temperature of the human body. In the same way, the bioreactors were put onto stir plates to keep them in constant shaking at $50 \mathrm{rpm}$. The system was installed into a laminar flow cabinet to maintain the sterility conditions. The first reactor contained the human stomach simulation in vitro and second one hold the human small intestine simulation in vitro, which was connected to a flexible tubing of $1 \mathrm{~cm}$ internal diameter to simulate the intestinal peristalsis by means of a peristaltic pump that worked at $50 \mathrm{rpm}$.

Food and beverage samples design (stimulant and alcoholic) used to evaluate the effect on Lactobacillus delbrueckii's viability: With the purpose of evaluating the effect of other kinds of food with the functional food that contains lactic probiotic bacteria and to simulate the nutritional habits of people that consume functional food, three samples of food and two beverages (stimulant and alcoholic) samples were tested. The food samples designed were: a $8 \%$ starch solution, cow milk with $8 \%$ starch and a typical Mexican food like "chilaquiles". The samples of cow milk with starch were designed with a texture similar to that of yoghurt. At the end of the sterilization process, this sample kept its viscous consistency with no precipitation of the milk proteins. The typical Mexican food was designed with the following composition: $75 \mathrm{~g}$ of tortilla, $20 \mathrm{~g}$ of chicken and $5 \mathrm{~g}$ of serrano hot pepper.

On the other hand, the sample of stimulant beverage consisted of $1 \%$ sterile black coffee solution, while the alcoholic beverage sample consisted of beer with $4.5 \%$ alcohol. All the samples were evaluated in separated treatments.

Cellular viability technique: To determine the viable counts of Lactobacillus delbrueckii, $1 \mathrm{~mL}$ of broth culture was taken and it was diluted with $9 \mathrm{~mL}$ of $0.9 \%$ $(\mathrm{p} / \mathrm{v})$ sterile saline solution. From this solution several dilutions were made and $0.1 \mathrm{~mL}$ of each one was inoculated by extension in Petri plates with MRS agar $(2 \% \mathrm{p} / \mathrm{v})$. The plates were incubated at $38^{\circ} \mathrm{C}$ for $48 \mathrm{~h}$; at the end of the incubation the Lactobacillus delbrueckii colonies were counted and the results were reported as percentage of bacterial viability.

Viability of Lactobacillus delbrueckii under in vitro simulated human gastrointestinal conditions: Kinetics of viability loss of Lactobacillus delbrueckii cells were made. For 90 min the cells were treated in simulated gastric conditions in vitro $(3 \%$ pepsin SIGMA-Aldrich P7000, 4\% mucin SIGMA-Aldrich $\mathrm{M} 2378,0.5 \% \mathrm{NaCl}$ adjusting the $\mathrm{pH}$ to 2.0 with $5 \mathrm{M}$ 
$\mathrm{HCl}$ ) with $100 \mathrm{~mL}$ of food or beverage at $37^{\circ} \mathrm{C}$ with continuous shaking at $50 \mathrm{rpm}$. Subsequently, the cells were treated for $150 \mathrm{~min}$ under intestinal conditions in vitro (1\% pancreatin SIGMA-Aldrich P1500, 4\% mucin, $0.3 \%$ bilis Oxgall Difco 212820 and $0.5 \% \mathrm{NaCl}$ adjusting the $\mathrm{pH}$ to 6.8 with $1.5 \mathrm{M} \mathrm{NaOH}$ ) at the same temperature and also with constant shaking conditions. At this stage the peristaltic movement in the human small intestine was simulated with a peristaltic pump that worked at $50 \mathrm{rpm}$. During the kinetics $1 \mathrm{~mL}$ of sample was taken every $30 \mathrm{~min}$ to determine the bacterial viability by plate count using MRS agar. The results were expressed in a percentage of viability and graphics were made in order to determine the rate of viability loss which was expressed in \% viability loss $/ \mathrm{min}^{-1}$. The blank was a sample of Lactobacillus delbrueckii cells exposed to simulated gastrointestinal conditions in vitro.

Statistical analysis: The experiments were made by triplicate and the results expressed in percentage of viability. The program SPSS version 12.0 was used to do the statistical analysis; an ANOVA of repeated measurements was applied to determine the significant statistical differences between the treatments. The Duncan multiple range test was used to identify those treatments in which differences were found. The data was analyzed with a $5 \%$ of significance level.

\section{RESULTS}

Viability of Lactobacillus delbrueckii under in vitro simulated human gastrointestinal conditions: The Table 1 and Fig. 1 show the results of viability of Lactobacillus delbrueckii cells treated in gastric and in intestinal conditions in vitro and in presence of the follow samples: starch solution, cow milk with starch, typical Mexican food (chilaquiles), black coffee and beer; the blank sample was Lactobacillus delbrueckii cells.

At the beginning of the kinetics of viability loss of Lactobacillus delbrueckii, the cellular concentration of the starch solution was $1.96 \times 10^{9} ; 1.27 \times 10^{9}$ and $1.25 \times 10^{9} \mathrm{UFC} \mathrm{mL}^{-1}$ for the starch with cow milk and the black coffee, respectively. In the case of the typical Mexican food, the concentration of viable cells corresponds to $1.92 \times 10^{9}$ and $5.38 \times 10^{9} \mathrm{UFC} \mathrm{mL}^{-1}$ to the blank sample. At the end of the treatment in simulated gastric conditions in vitro (90 $\mathrm{min}) 40 \%$ $\left(5 \times 10^{8} \mathrm{UFC} \mathrm{mL}^{-1}\right)$ and $29 \%\left(6.18 \times 10^{8} \mathrm{UFC} \mathrm{mL}^{-1}\right)$ of the cells treated in presence of cow milk with starch and a starch solution kept their viability, while $28 \%$ $\left(1.43 \times 10^{9} \mathrm{UFC} \mathrm{mL}^{-1}\right)$ of the cells of the blank remained viable; this means 1.4 times less viability than the cells treated with a sample of cow milk with starch. When the Lactobacillus delbrueckii cells were mixed with a sample of black coffee and typical Mexican food they preserved $67 \%\left(8.45 \times 10^{8} \mathrm{UFC} \mathrm{mL}^{-1}\right)$ and $80 \%$ $\left(1.5 \times 10^{9} \mathrm{UFC}^{-1}\right)$ of their viability, respectively. At the end of the treatment in intestinal conditions in vitro, the cells treated with a starch solution and the cells of the blank preserved $1 \%$ of their viability, while the cells treated with a sample of cow milk with starch and black coffee, kept 2 and 6.5 times more viability that the blank. With the addition of a sample of "chilaquiles", $73 \%\left(1.43 \times 10^{9} \mathrm{UFC} \mathrm{mL}^{-1}\right)$ of Lactobacillus delbrueckii cells remained viable at the end of the kinetic. This means 73 times more viability than the blank and 36.5 times more viability than the cells treated with the addition of a sample of cow milk with starch, at the same simulated gastrointestinal conditions in vitro. Nevertheless, Lactobacillus delbrueckii cells completely lost their viability when they were treated with a sample of beer and in gastric juice in vitro (these results are not presented in the Fig. 1).

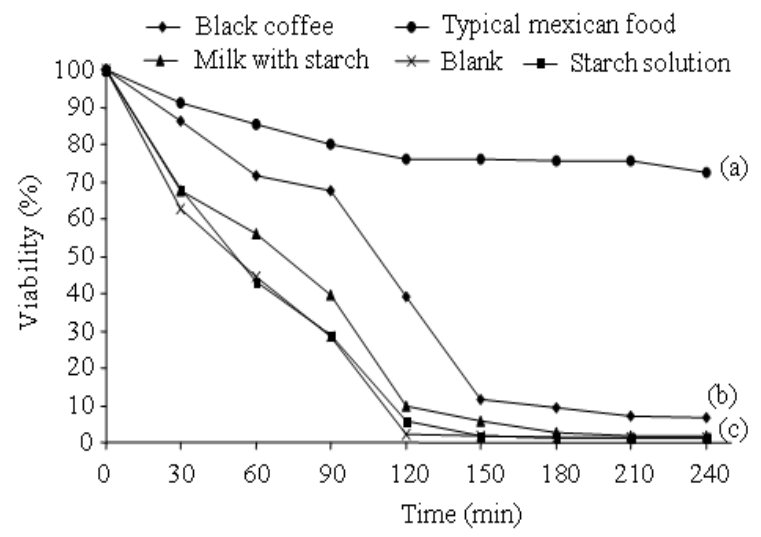

Fig. 1: Viability of Lactobacillus delbrueckii exposed to in vitro simulated human gastrointestinal conditions and in presence of several samples of food and beverages

Note: $\mathrm{n}=3$, the letters $(\mathrm{a}, \mathrm{b}, \mathrm{c})$ indicate that there are significant statistical difference between the viability of the several treatments, Duncan ( $\mathrm{p}<0.05)$. Treatments: starch solution, cow milk with starch and the blank did not reflect any significant statistical difference (a). Treatments in presence of $1 \%$ black coffee (b) and in presence of typical Mexican food (c), reflected significant statistical difference 
Am. J. Agri. \& Biol. Sci., 5 (1): 3-42, 2010

Table 1: Viability of Lactobacillus delbrueckii cells exposed to in vitro simulated human gastrointestinal conditions

\begin{tabular}{lccccc}
\hline Time $(\mathrm{min})$ & Blank $^{\mathrm{a}}(\%)$ & Starch solution $^{\mathrm{a}}(\%)$ & Starch/cow milk $^{\mathrm{a}}(\%)$ & Typical mexican food $^{\mathrm{c}}(\%)$ & Black coffee $^{\mathrm{b}}(\%)$ \\
\hline 0 & $100 \pm 00.0$ & $100 \pm 0.00$ & $100 \pm 0.00$ & $100 \pm 0.00$ & $100 \pm 00.0$ \\
30 & $63 \pm 10.9$ & $68 \pm 6.99$ & $68 \pm 5.35$ & $91 \pm 5.62$ & $86 \pm 17.8$ \\
60 & $45 \pm 05.2$ & $43 \pm 8.16$ & $56 \pm 3.01$ & $85 \pm 7.49$ & $72 \pm 16.0$ \\
90 & $28 \pm 09.7$ & $29 \pm 7.13$ & $40 \pm 2.72$ & $70 \pm 10.85$ & $67 \pm 17.1$ \\
120 & $02 \pm 00.5$ & $06 \pm 3.58$ & $10 \pm 0.86$ & $76 \pm 8.52$ & $39 \pm 11.1$ \\
150 & $02 \pm 00.2$ & $02 \pm 0.80$ & $06 \pm 1.88$ & $75 \pm 8.58$ & $11 \pm 07.5$ \\
180 & $01 \pm 00.2$ & $01 \pm 0.45$ & $02 \pm 1.31$ & $75 \pm 8.58$ & $09 \pm 06.8$ \\
210 & $01 \pm 00.1$ & $01 \pm 0.33$ & $02 \pm 0.30$ & $73 \pm 10.69$ & $07 \pm 04.3$ \\
240 & $01 \pm 00.0$ & $01 \pm 0.20$ & $02 \pm 0.30$ & $07 \pm 03.5$ \\
\hline
\end{tabular}

Note: The results presented are the average of 3 repetitions \pm DE; The treatments marked with ${ }^{(a, b, c)}$ show that there were significant statistical differences of viability. Duncan $(\mathrm{p}<0.05)$

Table 2: Rate of viability loss of Lactobacillus delbrueckii cells under in vitro simulated human gastrointestinal conditions

\begin{tabular}{|c|c|c|c|c|c|}
\hline \multirow[b]{2}{*}{ Period (min) } & \multicolumn{5}{|c|}{ (Percentage of viability loss $/ \mathrm{min}^{-1}$ ) } \\
\hline & Blank & Starch solution & Cow milk/starch & Typical mexican food & Black coffee \\
\hline $0-30$ & 1.247 & 1.072 & 1.080 & 0.291 & 0.457 \\
\hline $30-60$ & 0.605 & 0.818 & 0.393 & 0.204 & 0.485 \\
\hline $60-90$ & 0.148 & 0.485 & 0.536 & 0.177 & 0.144 \\
\hline $90-120$ & 0.865 & 0.768 & 0.997 & 0.124 & 0.947 \\
\hline $120-150$ & 0.024 & 0.136 & 0.136 & 0.000 & 0.921 \\
\hline $150-180$ & 0.008 & 0.012 & 0.109 & 0.021 & 0.070 \\
\hline $180-210$ & 0.002 & 0.003 & 0.028 & 0.000 & 0.074 \\
\hline
\end{tabular}

Note: The results showed the average of 3 repetitions \pm DE

The ANOVA of repeated measurements indicated that there existed significant statistical difference between the viability of Lactobacillus delbrueckii cells treated in simulated gastrointestinal conditions in vitro $\left(\mathrm{F}_{1,4}=102.615, \mathrm{p}<0.0001\right)$. In the same way, the Duncan test proved that there were not significant statistical differences between the viability of the Lactobacillus delbrueckii cells exposed to gastrointestinal juices (blank), starch solution and cow milk with starch. However, there were significant statistical differences in reference to the viability of cells treated in presence of black coffee and typical Mexican food (Duncan, $\mathrm{p} \leq 0.05$ ).

The estimated rates of viability loss for the different treatments of Lactobacillus delbrueckii cells treated in simulated gastrointestinal conditions in vitro were higher during two periods: At the beginning of the stage in simulated gastric conditions in vitro from 0 to $30 \mathrm{~min}$ and at the beginning of the stage in simulated intestinal conditions from 90-120 min (Table 2).

\section{DISCUSSION}

Lactobacillus delbrueckii lost its viability quickly when it was treated in simulated gastric conditions (simulated stomach in vitro) in presence of a starch solution sample. A similar effect was observed in the blank treated in the same gastric conditions in vitro. With the addition of a sample of cow milk and starch, the viability of Lactobacillus delbrueckii cells was higher than the viability of cells of the blank and the viability of cells treated in presence of starch solution. With a sample of typical Mexican food, the viability was 36.5 times more than the viability of Lactobacillus delbrueckii cells treated in presence of a sample of starch solution and in simulated gastrointestinal conditions in vitro. During the first $30 \mathrm{~min}$ of the stage in simulated small intestine conditions in vitro, the Lactobacillus delbrueckii cells were treated in intestinal juices and in presence of a sample of starch solution and cow milk with starch, quickly loosing their viability, falling from $29 \%$ to $6 \%$ and from $40 \%$ to $10 \%$ respectively; as for the blank, the viability fell from $28 \%$ to $2 \%$. In the case of the sample of cells treated with addition of black coffee, the most aggressive effect over bacterial viability appeared between the 90 and 150 min of the kinetic (intestinal conditions in vitro).

This study showed that when a sample of typical Mexican food like "chilaquiles" was added to the simulation system, the aggressive effect of the simulated intestinal conditions on the Lactobacillus delbrueckii viability diminished, thus at the end of the treatment, the bacterial viability was significantly higher compared with the cells viability in the other treatments.

The fast loss of bacterial viability during the first 30 min of the stages of simulated stomach and the small intestine in vitro could be due to the fact that the 
Lactobacillus delbrueckii cells were treated first in an acid media $(\mathrm{pH} 2)$ and when the cells showed possible phase of adjustment they were exposed to more aggressive conditions (addition of hepatic bile and pancreatin, $\mathrm{pH}$ 6.8).

On the other hand, the protective effect of the sample of typical Mexican food could be attributed mainly to the slightly viscous consistency of the mixture of tortilla, chicken and hot pepper with the simulated gastrointestinal juices in vitro. This mixture interacted with the Lactobacillus delbrueckii cells and brought some physical protection to the cells from the aggressive effect of simulated gastrointestinal conditions in vitro evaluated in this study. Some authors mentioned that the matrix food might protect the lactic bacteria, such as the Bifidobacterium, of the acid $\mathrm{pH}$ present in the human stomach (Walker and Duffy, 1998). The protective effect could be explained by the fact that diffusion processes had a less effect between the reaction medium and the Lactobacillus delbrueckii cells, resulting in the high bacterial viability at the end of the treatments.

When a sample of $1 \%$ black coffee or cow milk with starch were added to the simulation system, the Lactobacillus delbrueckii viability was significantly lower in reference to the bacterial viability in presence of a sample of typical Mexican food. The mixture of gastrointestinal juices with the black coffee solution and the mixture with cow milk and starch did not have a viscous consistency such as in the "chilaquiles" treatment. Therefore, in these treatments possibly the diffusion processes were easier and then more interaction occurred between the environment and the Lactobacillus delbrueckii cells. When a sample of beer was added to the medium (simulated gastrointestinal juices in vitro), Lactobacillus delbrueckii lost its viability completely and this could be attributed to the presence of ethylic alcohol in the beer.

Other authors have observed similar behaviors of viability loss in different strains of lactic bacteria treated in simulated gastrointestinal conditions in vitro. Authors such as Mainville et al., (2005) reported that Bifidobacterium animalis treated in acid medium $(\mathrm{pH}$ 2) for $90 \mathrm{~min}$ conserved $52 \%$ of its viability. Strains like Lactobacillus rhamnosus, Lactobacillus kefir, Bifidobacterium longum and Bifidobacterium infantis totally lost their viability at the end of $15 \mathrm{~min}$ in acid environment ( $\mathrm{pH}$ 2.0). Mainville et al., (2005) also reported that Lactobacillus kefirgranum and Bifidobacterium infantis kept $4 \%$ and $1 \%$ of its viability respectively, at the end of a treatment of 90 min in environment with $0.3 \%$ bile Oxgall, whereas Lactobacillus kefir kept $78 \%$ of its viability treated under the same conditions. Marteau et al., (1997) reported that Lactobacillus delbrueckii subsp. bulgaricus kept approximately $30 \%$ of its viability after 70 min in simulated gastric juice in vitro $(\mathrm{pH} 2.1)$ with addition of pepsinogen $\left(370 \mathrm{U} \mathrm{mL}^{-1}\right)$.. They reported the total loss of Lactobacillus delbrueckii viability after $110 \mathrm{~min}$ in simulated gastric juice in vitro (pH 1.8) with the addition of pepsinogen.

\section{CONCLUSION}

The in vitro simulation system designed in this study made possible to study the principal factors that may affect Lactobacillus delbrueckii subsp. bulgaricus NRRL-734. Some of these factors are the acid $\mathrm{pH}$ in the stomach and the hepatic bile in the small intestine, also, the presence of some important digestive enzymes such as pepsin and pancreatin. It was possible to suggest that Lactobacillus delbrueckii could survive in a high number and reach the colon when it is consumed together with similar food like those evaluated in this study. Future research on the same lines to determine the effects of typical food on the viability of the probiotics that are contained in functional foods will make it possible to establish recommendations to the consumer on how to consume the functional food, thereby allowing the survival of a higher quantity of viable probiotic lactic bacteria and at the same time on how to obtain higher benefits for probiotics consumers.

\section{AKNOWLEDGEMENT}

The authors thank the Instituto Politécnico Nacional for the financial and for the PIFI program support to develop the SIP projects (20082706, 20070160 and 20060651); and moreover to the United States Department of Agriculture for the donation of the strain.

\section{REFERENCES}

Aattouri, N., M. Bouras, D. Tome, A. Marcos and D. Lemonnier, 2002. Oral ingestion of lactic acid bacteria by rats increases lymphocytic proliferation and interferon and production. Br. J. Nutr., $\quad 87$ : 367-373. http://www.ncbi.nlm.nih.gov/pubmed/12064346

Casas, I.A. and W.J. Dobrogosz, 2000. Validation of the probiotic concept: Lactobacillus reuteri confers broad-spectrum protection against disease in humans and animals. Microbial. Ecol. Health Dis., 12: $247-285$. DOI: $10.1080 / 08910600050216246$ 
Chandramouli, V., K. Kailasapathy, P. Peiris and M. Jones, 2004. An improved method of microencapsulation and its evaluation to protect Lactobacillus spp. in simulated gastric conditions. J. Microbiol. Methods, 56: 27-35. DOI: 10.1016/J.MIMET.2003.09.002

De Boever, P., B. Deplancke and W. Verstraete, 2000. Fermentation by gut microbiota cultured in a simulator of the human intestinal microbial ecosystem is improved by supplementing a soygerm powder. J. Nutr., 130: 2599. http://jn.nutrition.org/cgi/reprint/130/10/2599

Dave, R.I. and N.P. Shah, 1998. Ingredient supplementation effects on viability of probiotic bacteria in yogurt. J. Dairy Sci., 81: 2804-2816. http://jn.nutrition.org/cgi/reprint/130/10/2599

Fávaro-Trindade, C.S. and C.R.F. Grosso, 2002. Microencapsulation of L. acidophilus (La-05) and $B$. lactis (Bb-12) and evaluation of their survival at the $\mathrm{PH}$ values of stomach and in bile. $\mathrm{J}$. Microencpasulation., $\quad$ 19: 485-494. http://www.ingentaconnect.com/content/apl/tmnc/2 002/00000019/00000004/art00008.

Hamilton-Miller, J.M.T., S. Shah and J.T. Winkler, 1999. Public health issues arising from microbiological and labeling quality of foods and supplements containing probiotic microorganisms. Public. Health Nutr., 2: 223-229. http://www.ncbi.nlm.nih.gov/pubmed/10447251?d $\mathrm{opt}=$ Abstract.

Huang, Y. and M. Adams, 2004. In vitro assessment of the upper gastrointestinal tolerance of potential probiotic dairy propionibacteria. Inter. J. Food Microbiol., $\quad$ 91: 253-260. DOI: 10.1016/J.IJFOODMICRO.2003.07.001

Iyer, C., M. Phillips and K. Kailasapathy, 2005. Release studies of Lactobacillus casei strain Shirota from chitosan-coated alginate-starch microcapsules in ex vivo porcine gastrointestinal contents. Lett. Appl. Microbiol., 41: 493-497. http://www.ncbi.nlm.nih.gov/pubmed/16305676?d opt=Abstract
Kailasapathy, K. and S. Rybka, 1997. Lactobacillus acidophilus and Bifidobacterium spp.: Their therapeutic potential and survival in yogurt. Aust. J. Dairy Technol., 52: 28-35. http://cat.inist.fr/?aModele=afficheN\&cpsidt=2646 595

Mainville, I., Y. Arcand and E.R. Farnworth, 2005. A dynamic model that simulates the human upper gastrointestinal tract for the study of probiotics. Inter. J. Food Microbiol., 99: 287-296. DOI: 10.1016/J.IJFOODMICRO.2004.08.020

Man, J.C. and M. E Rogosa, 1960. A medium for the cultivation of lactobacilli. J. Appl. Bact., 23: 130-135. www.sigmaaldrich.com/etc/medialib/docs/Fluka/... /69966dat.pdf

Marteau, P., M. Minekus, R. Havenaar and J. Huis in't Veld, 1997. Survival of lactic acid bacteria in a dynamic model of the stomach and small intestine: Validation and the effects of bile. J. Dairy Sci., 80: 1031-1037. http://jds.fass.org/cgi/reprint/80/6/1031

Minekus, M., P. Marteau, R. Havennar and J. Huis in't Veld, 1995. A multicompartmental dynamic computercontrolled model simulating the stomach and the small intestine. Alternatives Lab. Anim.., 23: 197-209. http://altweb.jhsph.edu/publications/journals/atla/2 3_2/atla23_2b.htm

Ouwehand, A.C. and S.J. Salminen, 1998. The health effects of cultured milk products with viable and non-viable bacteria. Int. Dairy J., 8: 749-758. DOI: 10.1016/S0958-6946 (98)00114-9

Sanders, M.E. and T.R. Klaenhammer, 2001. Invited review: The scientific basis of Lactobacillus acidophilus NCFM functionality as a probiotic. J. Dairy Sci., 84: 319-331. DOI: 10.1016/S0168-1605 (00)00380-9

Walker, A.W. and L.C. Duffy, 1998. Diet and bacterial colonization: Role of probiotics and prebiotics. Rev. J. Nutr. Biochem., 9: 668-675. DOI: 10.1016/S0955-2863 (98)00058-8. 